\title{
Early Child Development: A Framework for Collaboration
}

\author{
Mary Eming Young \\ World Bank \\ USA
}

\begin{abstract}
The convergence of knowledge from neuroscience, social science and economics on the importance of early life or experiences on brain development has tremendous implication on the future of societies. Regardless of their level of development or income, countries must provide ECD programs for all the children and involve parents and caregivers in these efforts. Each country along the continuum of development has a responsibility to (i) identify factors within its society and culture that inhibit healthy child development and (ii) create building blocks for a national ECD system. Moreover, it is important to recognize that the new knowledge has implications for all sectors, including tertiary education.
\end{abstract}

Key words : early human (child) development, economic benefits, comprehensive ECD programs

\section{Investing in Early Child Development - the Benefits}

The exponential growth in knowledge from developmental neuroscience, biological science, and epigenetics provides the scientific underpinning for understanding the importance of early child development and the value of programs that foster healthy development (Mustard, 2007). Early child development (ECD) programs for young children (ages 0-8 years) are an investment in the future and a cost-effective strategy for economic development.

The integration of nurturance, care, health, stimulation, and education in comprehensive ECD programs for young children contributes ultimately to full participation in the labor force and, thereby, a

Correspondence concerning this article should be addressed to Mary Eming Young, MD DrPH, Lead Child Development Specialist, The World Bank, 1818 H St., N.W. MSN \# J3-302, Washington, D.C. 20433, U.S.A. Electronic mail may be sent to myoung3@worldbank.org nation's economic growth and productivity. The implications of this connection for human capital formation are immense and are articulated in a wide range of publications, from lay articles to academic reports (The Economist, 2006; Augustine, 2007).

Cost-benefit analyses and rate-of-return calculations strengthen the evidence that ECD programs foster human development (i.e., human capital skills) and save governments' money in the long term. Finance and business leaders consider early human services (i.e., ECD programs) to be critical to the development of a country's labor force. They cite ECD as an economic development strategy (not simply a social policy) similar to other, traditional "hard"-sector investments such as transportation and urban development (Coffey 2007; Grunewald \& Rolnick, 2007).

The economic returns to early childhood interventions are high. Nobel laureate James J. Heckman summarizes the benefits of early interventions clearly: early learning is more 
productive than later learning; waiting until kindergarten or primary school may be too late to intervene; and early education is far more effective and promises greater returns than remedial training later (Carneiro \& Heckman, 2003) (figure 1).

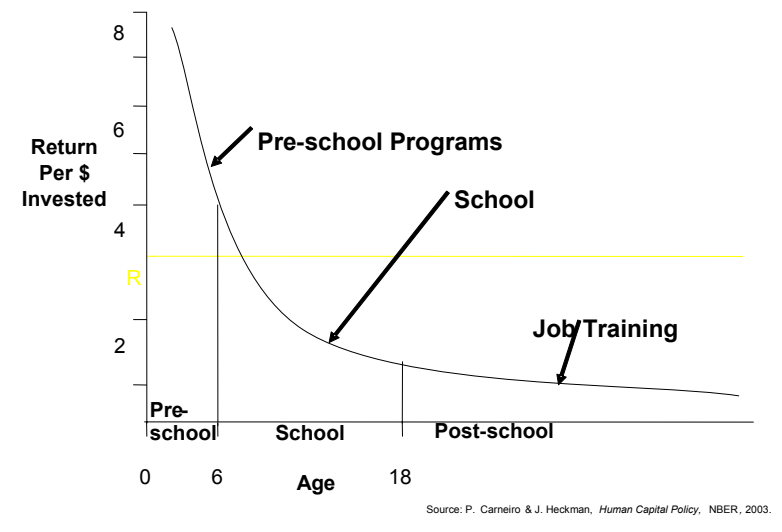

Figure 1. Rates of Return to Human Development- Investment Across All Ages

Extensive evidence demonstrates that investing in children's early years has the highest rates of return and that not investing in these years is the most costly failure of policies for human capital formation (Bordoff, Furman, \& Bendor, 2007). Investments in early human development are essential for:

- Creating knowledge workers

- Improving populations' health and reducing health care costs

- Achieving equity

\section{Creating Knowledge Workers}

Social scientists, economists (including the Nobel laureates Fogel, Heckman, and Sen), and business leaders argue that early childhood is particularly important for acquiring cognitive and non-cognitive skills (e.g., critical thinking, problem-solving, interpersonal, teamwork) that are essential attributes of knowledge workers and labor forces of the $21^{\text {st }}$ century as nations compete in the global marketplace. Studies show that investments in early childhood are likely to more than pay for themselves in subsequent decades. Figure 2 summarizes the rates of return from several longitudinal studies of ECD programs in the United States.

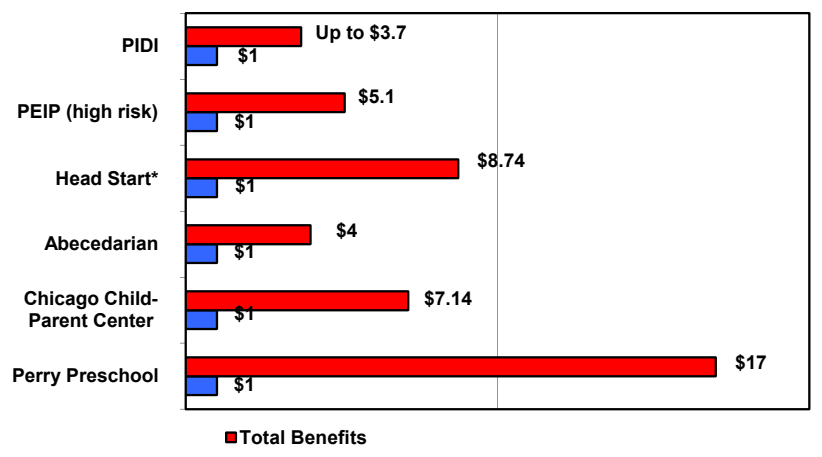

Figure 2. Cost Benefit Analysis of Early Child Development Programs in the United States

Note From: Behrman, Cheng, E Todd, 2004; Karolyi et al., 2001; Meier 2003.

\section{Improving Populations' Health and Reducing Health Care Costs}

The benefits of early human development do not end at educational achievement. Rather, brain development in the early years sets trajectories that affect health throughout life. Epidemiological studies show that low birthweight and weight gain during infancy have an impact on chronic disease in adulthood. For example, thinness at birth and during infancy is associated, in adult life, with increased rates of coronary heart disease, stroke, type 2 diabetes mellitus, adiposity, metabolic syndrome, and osteoporosis (Gluckman, Hanson, Cooper, \& Thornburg, 2008).

Equally important for the development of young children are good nutrition and good health. Malnutrition (e.g., micronutrient deficiencies) can impair children's ability to learn, think, socialize, and explore their environments. Negative effects of malnutrition prenatally and during the first $2-3$ years of life are especially hard-felt and may lead to irreversible consequences. Poor nutrition at these times is shown to be related to delays in physical and 
motor development, impaired intellectual ability, problems with concentration, and poor social skills (Hoddinott, Maluccio, Behrman, Flores, \& Martorell, 2008).

\section{Achieving Equity}

Early human development is a powerful equalizer. Investments in early childhood yield significant longterm benefits that narrow the gap between high- and low-income families. Nobel laureate Heckman (2006) notes that investing in disadvantaged young children "... is a rare public policy initiative that promotes fairness and social justice and at the same time promotes productivity in the economy and in society at large." The World Health Organization (WHO) Commission on Social Determinants of Health states that closing the inequity gap in one generation is doable, provided we start with a more comprehensive approach to the early years in life-that is, "equity from the start" (CSDH, 2008).

\section{Calls to Action}

Recent calls for action come from different venues, and they are numerous. Publications on the importance of early brain development have surged in the global ECD community and have stimulated both increased ECD programming by multilateral and bilateral agencies and focused policy action by countries in all world regions. Some of the major calls to action are noted below. We must build on them.

The World Bank, for example, highlights the state of the science in early child development and the rationale for investing in ECD programs. The recommendations, presented in a series of publications, derive from three global conferences on early child development (Young, 1997, 2002, \& 2007).

The United Nations Children's Fund (UNICEF) reports on the state of the world's children in early childhood (UNICEF, 2001). The United Nations Educational, Scientific, and Cultural Organization
(UNESCO) calls for strong foundations in early childhood care and education (UNESCO, 2006).

World leaders in early child development come together for a three-part series in The Lancet, a leading international journal, to review and present evidence showing that promotion of cost-effective ECD programs, which includes the scaling up of investments in young children, is a priority for the global development agenda (Grantham-McGregor et al., 2007; Walker et al., 2007; Engle et al., 2007). This series is followed by additional focus in the same journal on the importance of nutrition in healthy maternal and child development (Bryce et al., 2008).

The authors of the 2007 series in The Lancet conservatively estimate that, worldwide, more than 200 million children under age 5 fail to reach their developmental potential because of poverty, poor health and nutrition, and lack of early stimulation. Most of the children (89 million) live in South Asia, and many more (71 million) live in Sub-Saharan Africa. The highest prevalence of disadvantaged children under age 5 is in Sub-Saharan Africa (61 \%), followed by South Asia (52\%). Ten countries alone (India, Nigeria, China, Bangladesh, Ethiopia, Indonesia, Pakistan, Democratic Republic of Congo, Uganda, and Tanzania) account for 145 million (66\%) of the 219 million disadvantaged children in the developing world.

Most recently, WHO's Commission on Social Determinants of Health (CSDH) emphasizes that healthy early development is a powerful equalizer (CSDH, 2008). It sets out practicable recommendations for countries to adopt comprehensive ECD programs (Irwin, Siddiqi, \& Hertzman, 2007).

Despite this upsurge of global initiatives and publications and an enhanced global awareness of the importance of early child development, much more still needs to be done to close the gap between "what we know and what we do." A major challenge for many countries is to ensure that all sectors of society understand the meaning of this revolution in scientific 
understanding of ECD for public policies affecting human development and population quality.

Often the dilemma raised by policymakers in lowincome countries is how to give priority to investing in young children when there are many urgent and competing issues, such as high burdens of disease, low rates of child survival, poor participation and school performance in basic education, and limited infrastructures and resources. Indeed, in these countries, child survival has to be a high priority. Clean and adequate water supplies, safe sanitation systems, adequate nutrition, and immunization strategies are essential. But, as the body of knowledge on brain development shows, survival and development must be addressed concurrently, not, instead of and sequentially. One could ask: Survival for what? Children who survive, but are poorly nourished and stunted and have inadequate or poor early development and limited education, will become poor parents, perpetuating the cycle of poverty and its effects.

Furthermore, because of the importance of early experiences on brain development, societies, regardless of their level of development or income, must provide ECD programs for all the children who survive-and involve parents and caregivers in these efforts. Each country along the continuum of development has a responsibility to (i) identify factors within its society and culture that inhibit healthy child development and (ii) create building blocks for a national ECD system.

Across countries, key inhibitors include a lack of understanding of the importance of early child development and ECD programs, poor economies and socioeconomic disparities, inadequate institutional structures to support families with young children, lack of financing and knowledge of innovative ways to pay for ECD services, social beliefs and cultural views that negatively affect education and young children, and professional and sectoral silos of activity that thwart development of integrated ECD policies and programs. Once these and other inhibitors are identified and understood, governments can envisage a national ECD system, and communities, educators, and policymakers can begin to create the necessary building blocks.

\section{A Framework for Collaboration across Sectors}

The experience of many countries in acting to create building blocks for a comprehensive, integrated approach to early child development points to the need for a framework of collaboration across sectors and silos within countries. This overall framework must be grounded in the science of early child development, and both public and private sectors must be engaged. No one sector can do it all, and no single blueprint can possibly fit the specific needs of every country. Yet, the overall framework applies to all and reflects the experience of many. To build national ECD systems, all countries will need to do the following:

1. Shift the education paradigm and involve parents in children's development.

2. Expand services to include children under age 3 and parent education.

3. Assure quality programming through training.

4. Institute a monitoring system to measure population-level outcomes of children's development.

It is important to realize that the new knowledge about early child development has implications for all sectors, including tertiary education (e.g., in the health sciences, economics, social sciences, education, and developmental psychology) and government policymaking related to quality of the labor force. The private sector needs to be engaged, and private-public partnerships could accelerate action by combining private-sector resources and know-how with publicsector policies and strategies. For each part of the framework, some necessary actions are described below. 


\section{Shift the Education Paradigm}

The current education paradigm centers on obtaining specific academic knowledge, and achievement is often assessed by examination. In today's post-industrial societies, we need to rethink education and focus on the process of learning-and foster development of those essential attributes that knowledge workers need to compete in the global marketplace. A paradigm for the $21^{\text {st }}$ century is based on the recognition that learning begins well before a child enters school and that social and emotional skills are as necessary as cognitive skills in the development of young children. Two specific actions are:

- Expand coverage and enhance the quality of entire educational systems. Alignment of the curricula for early childhood education, from preschool through primary school and at least through grade 3, would add value at each level and help to assure children's performance throughout school.

- Foster positive development of social and emotional, as well as cognitive skills. Redirect the focus of preschool from teacher-led, didactic and rote learning of traditional texts to play-based, interactive child-teacher engagements centered on the child.

\section{Expand Services to Include Children under Age 3 and Parent Education}

Services for young children ages 0-6 must be expanded. A specific blueprint to meet the needs of all children everywhere is not possible. Programs and interventions must accommodate local conditions (e.g., children's developmental outcomes, social and educational infrastructures) and differences between population groups, rural and urban areas, and income levels. Specific actions are:

- Launch a coordinated, systematic process for collecting and analyzing data on the needs of children across all population groups in a country. Use these data to develop ECD policies and to expand and scale up effective ECD programs.

- Devise a broad strategy that would necessarily start in the early years, depart from a singlesilo approach (i.e., education, health, or social protection), and move toward a comprehensive package of ECD services. This package should comprise breastfeeding and nutritional support; stimulation (i.e., interaction between caregivers and children); comprehensive support to and care of mothers (before, during, and after pregnancy); support of parents and caregivers; and play-based child development services. The education sector should provide quality pre-primary education that attends to each child's physical, social, emotional, and language development.

\section{Assure Quality through Training}

The quality of ECD programs depends on the quality of teachers and training in ECD. Too often, quality is equated with structural indicators (e.g., staff-to-child ratio, group size, accreditation, staff credentials), administrative indicators (e.g., record keeping, compliance with regulations), and resources available (square footage per child, presence of "learning centers," equipment and supplies).

However, quality and training are paramount. An essential minimum, and often overlooked, ingredient is how staff and children interact throughout the day and how safe and healthy their environment is. Effective interactions and healthy environments are achievable in even the lowest-income preschool settings. School interactions and environments directly reflect staff training. To strengthen and reform ECD services, a specific action is:

- Provide formal pre-training and continuing inservice training for ECD educators and staff. For example, a multimedia training program entitled "The Science of Early Child Development" has been used to improve understanding of experienced-based brain 
development on child development in industrialized and developing countries. Originally developed for education and training of ECD practitioners in Canada, the program has been adapted and used for parents and communities in countries in Central Asia, South Asia, and East Africa. The program is produced by Red River College in Winnipeg, Manitoba (http://www. scienceofecd.com).

\section{Monitor Population-Level Outcomes of Children's Development}

To support decisionmaking and development of policies for early human development and childhood education, countries need a system for assessing and monitoring children's readiness for school (and readiness to learn). Children's developmental outcomes between ages 0 and 6 are the "launching pad" for success in school and life. By introducing and applying a comprehensive population-based assessment of children's outcomes by the time they reach kindergarten, countries could use the data, for example, to identify geographic areas and population groups with the greatest number of young children at risk of, or vulnerable for, poor school performance. This information is essential for designing and targeting ECD services and for monitoring the outcomes of children receiving these services.

A population-based measurement tool is available and is being used and tested in various countries. This “Early Development Instrument: A Population-based Measure for Communities (EDI)" is the infantmortality-rate equivalent for children's early development. The EDI is the only available ECD outcome measure that assesses, in one instrument, the universally recognized five key developmental domains-physical health and well-being, social competence, emotional maturity, language and cognitive development, and communication skill and general knowledge. With a population-based instrument such as the EDI, communities and countries can:

- Delineate and understand ECD determinants in families, neighborhoods, and society. The determinants are complex and are expressed differently in different settings (Irwin, Siddiqi, \& Hertzman, 2007). Using a population-based assessment, one can identify what and where the differences are that determine different outcomes. The ultimate goal is to apply this understanding to improve developmental trajectories for individuals and populations and to offer, monitor, and ensure equal opportunities for all children.

- Develop a database of child development outcomes. This database will enable policymakers and governments to attain accountability, comparability, and universality of ECD services within countries. It also will facilitate comparisons and discussions of ECD as a global public good across countries.

A population-based assessment such as the EDI is a useful tool for collecting and analyzing data on groups of children (e.g., in a school, neighborhood, community, state, province). It is not applied to individual children (e.g., to screen or diagnose for, or to assign to, special education, extra assistance, or grade retention; recommend special teaching approaches; measure success or failure of preschool or childcare experience; design ECD curricula).

\section{Conclusion}

We now have solid evidence to justify an array of ECD programs and evaluations that draw on the latest knowledge of experience-based brain development. Four main messages are clear and are relevant to any decisions and policies concerning early child development. The messages are: 
- Invest in children's early years to take advantage of the malleability of their brains.

- Support development of capacity in early child development across disciplines and among caregivers.

- Build on foundations in the health sector - that is, add development to survival and understand that chronic disease has its roots in the early years of life.

- Align preschool with basic education and beyond, while shifting the education paradigm and expanding services.

Working together in collaboration, across sectors and silos, societies can promote effective policies that support the development of young children and the integrity of families. Government's role is to provide leadership and oversight (i.e., a governing structure) to coordinate ECD strategies that cross institutional borders and, guided by population-based assessments of children's development, link ECD outcomes to subsequent school performance. Broad strategies necessarily start with the early years, depart from a single-silo approach, involve families and communities, and aim for comprehensive packages of integrated ECD services. Such strategies would serve "mothers and others" and the evolution of "mutual understanding" to benefit all (Hrdy, 2009).

\section{References}

Augustine, N. R. (2007). Is America Falling Off the Flat Earth? Washington: The National Academies Press.

Behrman, J., Cheng, Y., \& Todd, P. (2004). Evaluating preschool programs when length of exposure to the program varies: A nonparametric approach. Rev Econ Stat, 86(1), 108-32.

Bordoff, J., Furman, J., \& Bendor, J. (2007). An education strategy to promote opportunity, prosperity, and growth. The Hamilton Project Strategy Paper. Washington, DC: The Brookings Institution.
Bryce, J., Coitinho, D., Darnton-Hill, I., Pelletier, D., \& Pinstrup-Anderson, P. (2008). Maternal and child undernutrition: Effective action at national level. The Lancet, 371(9611), 510-526.

Carneiro, P. M., \& Heckman, J. J. (2003). Human Capital Policy (Institute for the Study of Labor (IZA) Discussion Paper No. 821). Retrieved March 24, 2007, from http://papers.ssrn.com/sol3/ papers.cfm?abstract_id=434544]

Coffey, C. (2007). Early child development is a business imperative. In M. E. Young (Ed.), Early child development - From measurement to action. A priority for growth and equity (pp. 33-42). Washington, DC: The World Bank.

Commission on Social Determinants of Health (CSDH). (2008). Closing the gap in a generation: health equity through action on the social determinants of health. Final report of the commission on social determinants of health. Geneva: World Health Organization.

Engle, P. L., Black, M. M., Behrman, J. R., Cabral de Mello, M., Gertler, P. J., Kapiriri, L., et al. (2007). Strategies to avoid the loss of developmental potential in more than 200 million children in the developing world. The Lancet, 369(9557), 229-242.

Gluckman, P. D., Hanson, M. A., Cooper, C., \& Thornburg, K. L. (2008). Effect of in utero and early-life conditions on adult health and disease. $N$ Engl $\mathrm{J} \mathrm{Med}$, 359, 61-73.

Grantham-McGregor, S., Cheung, Y. B., Cueto, S., Glewwe, P., Richter, L., Strupp, B., et al. (2007). Developmental potential in the first 5 years for children in developing countries. The Lancet, 369(9555), 60-70.

Grunewald, R., \& Rolnick, A. (2007). A productive investment: Early child development. In M. E. Young (Ed.), Early child development - From measurement to action. A priority for growth and equity (pp. 17-32). Washington, DC: The World Bank.

Heckman, J. J. (2006, January). Investing in disadvantaged young children is an economically efficient policy. Paper presented at the Committee for Economic Development forum, Building the Economic Case for Investment in Preschool, New York. 
Hoddinott, J., Maluccio, J. A., Behrman, J. R., Flores, R., \& Martorell, R. (2008). Effect of a nutrition intervention during early childhood on economic productivity in Guatemalan adults. The Lancet, 371(9610), 411-416.

Hrdy, S. B. (2009). Mothers and others: The evolutionary origins of mutual understanding. Cambridge, MA: Harvard University Press.

Irwin, L. G., Siddiqi, A., \& Hertzman, C. (2007). Early child development: A powerful equalizer, final report for the World Health Organization's Commission on the social determinants of health. Vancouver, Canada: Human Early Learning Partnership.

Jamieson, J., Bertrand, J., \& Ibrahim, E. (Eds). (2008). The Science of Early Child Development. Retrieved October 15, 2010, from http:// www.scienceofecd.com/

Karolyi, L. A., Kilburn, M. R., Bigelow, J. H., Caulkins, J. P., Cannon, J. S., \& Chiesa, J. (2001). Assessing costs and benefits of early childhood intervention programs. Santa Monica, Calif: Rand Corporation.

Meier, J. H. (2003, January). Success of Head Start School Readiness. Adapted from http:/www.nhsa.org/ files/static_page_files/F6139292-1D09-3519-

AD7C8873804B1AAF/Meier.pdf

Mustard, J. F. (2007). Experience-based brain development: scientific underpinnings of the importance of early child development in a global world. In M. E. Young (Ed.), Early child development - From measurement to action. A priority for growth and equity (pp. 43-84). Washington, DC: The World Bank.

The Economist. (2006, September 21). Epigenetics: Learning without learning.

United Nations Educational, Scientific, and Cultural Organization(UNESCO). (2006). Education for all global monitoring report 2007. strong foundations early childhood care and education. Paris: Author.

United Nations Children's Fund(UNICEF). (2001). The state of the world's children 2001: early childhood. NY: Author.

Walker, S. P., Wachs, T. D., Gardner, J. M., Lozoff, B., Wasserman, G. A., Pollitt, E., et al. (2007). Child development: risk factors for adverse outcomes in developing countries. The Lancet, 369(9556), 145-157. Young, M. E., (Ed.). (1997). Early child development: Investing in our children's future. Amsterdam: Elsevier Science B.V.

Young, M. E., (Ed.). (2002). From early child development to human development: Investing in our children's future. Washington, DC: The World Bank.

Young, M. E., Richardson, L. M. (Eds.). (2007). Early child development - from measurement to action. A priority for growth and equity. Washington, DC: The World Bank. 